
\title{
R Reserach S Suare \\ The Early-Life Risk Factors of Childhood Wheezing: Results from the NHANES During 2005-2012
}

Rahmatollah Moradzadeh

Arak university of medical science

Maryam Zamanian ( $\square$ zamanian.m2015@gmail.com )

Arak university of medical science https://orcid.org/0000-0002-9952-8483

Research article

Keywords: Wheezing, Childhood, Early-life risk factors, NHANES

Posted Date: July 6th, 2020

DOI: https://doi.org/10.21203/rs.3.rs-39732/v1

License: (9) (1) This work is licensed under a Creative Commons Attribution 4.0 International License.

Read Full License 


\section{Abstract}

Objectives: Wheezing is the most common cause of hospitalization during childhood. The aim of the present study was to identify early-life risk factors predisposing to childhood wheezing using directed acyclic graph (DAG) analysis.

Methods: In this study, we used the National Health and Nutrition Examination Survey (NHANES) data to identify the risk factors associated with wheezing in children aged 1-15 years old in the United States. The data was related to four 2-year cycles from 2005 to 2012. All the adjusted analyses were based on the directed acyclic graph(DAG). The applied logistic regression was performed by survey analysis to adjust the weights of samples.

Results: From 13203 children, 87.2\% $(n=11519)$ had not experienced wheezing during the past year, and $12.8 \%(n=1684)$ experienced wheezing during the same time. The mean ages (SD) were $6.6(4.4)$ and 7.6 (4.4) years old in wheezing and healthy children respectively. Boys comprised a significantly higher ratio in wheezing compared with healthy children $(P=0.001)$. Mother smoking during pregnancy (MSDP) was a significant risk factor for childhood wheezing $(\mathrm{OR}=1.42,95 \% \mathrm{Cl}: 1.15-1.74, \mathrm{P}=0.001)$. All ethnicities other than the Mexican-American were established as significant risk factors for childhood wheezing. On the other hand, childhood wheezing was insignificantly associated with Socio-economic status, birth weight, maternal age at pregnancy, and exposure to smoke at home.

Conclusion: After adjusting for established confounders, history of MSDP, as well as ethnicity delivered important risk factors for childhood wheezing in a large population of the US.

\section{Introduction}

Wheezing is most often triggered by the blockage of the lower respiratory tract (1). Wheezing can inflict anywhere in the intrathoracic trachea, induce inflammation and mucus production in the airways, and promote reversible tightening of the smooth muscles in the airways walls (2). The sound of wheezing is induced by the turbulent airflow in the large airways which collapse upon expiration. Due to smaller airways of children, wheezing is an important clinical condition in childhood (1).

Wheezing presents a global problem and a multifactorial disease (3). It is one of the most common causes of hospitalization during childhood (4). With the prevalence of about $26.4 \%$, wheezing comprises a common problem in children aging 2-3 years old in the United States (US). (5). The prevalence of childhood wheezing has been noted as $22.1 \%$ in United Kingdom (6). In order to prevent childhood wheezing, it is important to identify early-life risk factors for this phenomenon (3). In this study, we aimed to ascertain the early-life risk factors of childhood wheezing using a dataset of a large population from 2005 to 2012. Discrepancies have been observed in the estimated risk factors of childhood wheezing in previous studies. These discrepancies may be due to recruiting inappropriate inclusion criteria for variables in the analysis model. In this study, we tried to obviate this problem and avoid selection bias by 
using a multivariable analysis based on the directed acyclic graph (DAG) and modern epidemiology recommendations $(7,8)$.

The aim of the present study was to investigate the potential effects of some early-life factors, Socioeconomic status (SES), and ethnicity on childhood wheezing. For this, we used DAG analysis to identify possible confounding factors contributing to childhood wheezing. This was a large population-based survey performed on the data related to a large population in the US from 2005 to 2012.

\section{Methods}

\section{The study population and data acquisition}

The National Health and Nutrition Examination Survey (NHANES) represents a cross-sectional survey conducted on the US pediatric population. Details on the methodology have been described elsewhere $(9$, 10). In particular, NHANES is a population-based survey designed to assess the health status of the US population. The data of the NHANES study has been being collected at 2-year cycles since 1999. The NHANES interviews addressed the demographic, socioeconomic and other health related variables. The survey was designed as a stratified multistage probability study so that oversampled of certain age and minority groups.

In this study, we used NHANES data related to children aged 1-15 years living in the US. The analyzed data corresponded to four 2-year cycles from 2005 to 2012.

Regarding the four cycles of the survey, 13212 children aged 1 to 15 years old were interviewed (either the children themselves or their parents). Children were excluded if they had incomplete data on the wheezing status.

\section{The study variables}

The wheezing as the outcome variable was defined as self-reported wheezing or whistling in chest during the past year. During the interviews, the parents were asked: "In the past 12 months, have children had wheezing or whistling in their chest?". The response options included "yeas" and "no".

Other variables have been described in the following. The MSDP (did children biological mother smoke at any time during the pregnancy) was defined as a binary variable (yes / no). Race/ethnicity was categorized as Mexican-American, non-Hispanic white, non-Hispanic black, other Hispanic, and other (including multiracial status). Socio-economic status (SES) was estimated by the number of rooms in the house, annual household income, and the total number of family members. The SES was finally determined and categorized into five quartiles by merging these items through principle component analysis $(11,12)$. Birth weight was recorded as a continuous variable in pounds (How much did the child weigh at birth?). In addition, maternal age at pregnancy was categorized as $14-19,20-29,30-34$, and $\geq$ 40 years old. The children's ages were recorded in years. Also, the gender was collected as male or 
female. In the present analysis, the question of "Does anyone smoke at home? (Yes / No)" was incorporated to determine the exposure of children to smoke at home.

\section{Statistical analysis}

Directed acyclic graphs (DAGs) are valid causal inferences that are increasingly used in modern epidemiology $(10,13,14)$. In order to address confounding effects, the DAG was used to determine the variables eligible to be included in this study (Fig. 1). All the backdoor paths that were related to the studied variables were identified to disclose any confounding effect $(7,13)$. The impact of each of MSDP, SES, smoker family members, birth weight, maternal age at pregnancy, and ethnicity on childhood wheezing was calculated through conditioning by adjusting confounding paths in logistic regression analysis. For this purpose, the SES, smoker family members, and ethnicity, as the variable located on the confounding paths, were included in the logistic regression model to determine the impact of MSDP on childhood wheezing.

Furthermore, as the NHANES survey depends on the weighting approach (10), the applied logistic regression was run by survey analysis to calculate unadjusted and adjusted ORs and respective $95 \%$ confidence intervals ( $95 \% \mathrm{Cls}$ ) for potential confounders. By default, the sampling weighting in NHANES public dataset is specified at 2-year time intervals. Because the analysis was performed on four 2-year cycles, and in order to achieve valid weights, we transformed the 2-year weights into 8-year weights in compliance with the NHANES instructions. The analyses were performed in STATA 12.0 software.

\section{Results}

Of the 13212 children who were present at all the four cycles (i.e. eight years from 2005-2012), 13203 (99.93\%) had full data on wheezing status. Among these, $87.2 \%(n=11519)$ declared no wheezing or whistling in chest during the past year. On the other hand, $12.8 \%(n=1684)$ children experienced wheezing in the same period. Table 1 shows the characteristics of the study population stratified by wheezing status. 
Table 1

Characteristics of study population, NHANES, US, 2005-12.

\begin{tabular}{|c|c|c|c|c|c|}
\hline Variables & & $\begin{array}{l}\text { Wheezing } \\
\text { cases n (\%) }\end{array}$ & $\begin{array}{l}\text { Healthy } \\
\text { children n } \\
(\%)\end{array}$ & $\begin{array}{l}\text { Unadjusted } \\
\text { OR }(95 \% \mathrm{Cl})\end{array}$ & $\begin{array}{l}P \\
\text { value }\end{array}$ \\
\hline Age, mean (SD) & & $\begin{array}{l}6.6(4.4) n= \\
1684\end{array}$ & $\begin{array}{l}7.6(4.4) n= \\
11519\end{array}$ & $\begin{array}{l}0.96(0.95 \\
0.97)\end{array}$ & 0.001 \\
\hline \multirow[t]{3}{*}{ Sex } & Male & $1001(59.44)$ & $5690(49.40)$ & 1 (ref.) & \\
\hline & Female & $683(40.56)$ & $5829(50.60)$ & $\begin{array}{l}0.67(0.58 \\
0.78)\end{array}$ & 0.001 \\
\hline & Total & $1684(100)$ & $11519(100)$ & & \\
\hline \multicolumn{6}{|l|}{ Annual household income } \\
\hline & $\begin{array}{l}>= \\
\$ 20000\end{array}$ & 1233(74.37) & $8320(75.26)$ & 1 & \\
\hline & $\$_{\$ 20000}$ & $425(25.63)$ & $2735(24.74)$ & $\begin{array}{l}0.99(0.84 \\
1.17)\end{array}$ & 0.914 \\
\hline & Total & $1658(100)$ & $11055(100)$ & & \\
\hline \multirow{2}{*}{$\begin{array}{l}\text { Number of rooms in home, } \\
\text { mean (SD) }\end{array}$} & & $6.06(2.00)$ & $6.02(2.06)$ & \multirow{2}{*}{$\begin{array}{l}0.98(0.94 \\
1.03)\end{array}$} & \multirow[t]{2}{*}{0.45} \\
\hline & & $N=1678$ & $N=11424$ & & \\
\hline $\begin{array}{l}\text { Total number of people in the } \\
\text { family, mean (SD) }\end{array}$ & & $\begin{array}{l}4.42(1.39) n \\
=1684\end{array}$ & $\begin{array}{l}4.64(1.38) n \\
=11519\end{array}$ & $\begin{array}{l}0.92(0.87 \\
0.96)\end{array}$ & 0.001 \\
\hline
\end{tabular}

The mean ages (SD) were 6.6 (4.4) and 7.6 (4.4) years old in wheezing and healthy children respectively. The ratio of boys was significantly higher among the wheezing than healthy children $(P=0.001)$. The proportion of households with the annual income $\geq \$ 20000$ was higher in wheezing than healthy children $(P=0.914)$. The total number of family members was significantly lower in wheezing than healthy children $(P=001)$. Finally, the number of rooms per house was slightly higher in wheezing than healthy children $(P=0.45$, Table 1$)$.

All the adjusted analyses were based on the confounding paths identified in the DAG analysis (Fig. 1). The adjusted and unadjusted associations between each studied variable and wheezing status have been shown in Table 2. After adjusting for the effects of SES, smoker family members, and ethnicity, the MSDP remained an independent risk factor for childhood wheezing $(\mathrm{OR}=1.42,95 \% \mathrm{Cl}: 1.15-1.74, \mathrm{P}=$ 0.001). After adjusting for the impact of ethnicity, the higher SES status was associated with decreased odds of wheezing ( $\mathrm{OR}=0.98,95 \% \mathrm{Cl}$ : $0.93-1.02, \mathrm{P}=0.32$, Table 2$)$. Higher birth weight showed a protective role against childhood wheezing even after adjusting the effects of confounding paths (OR = $0.96,95 \% \mathrm{Cl}: 0.90-1.01, P=0.118)$. The maternal age at pregnancy was not significantly associated with childhood wheezing after adjustment for SES status and ethnicity. Similarly, there was no significant association between childhood wheezing and having smoker family member (Table 2). As indicated in 
Fig. 1, presuming that there were no confounding paths in determining the association between ethnicity and childhood wheezing, non-Hispanic White $(\mathrm{OR}=1.49,95 \% \mathrm{Cl}$ : $1.23-1.82, \mathrm{P}=0.001)$, non-Hispanic black $(\mathrm{OR}=2.03,95 \% \mathrm{Cl}: 1.63-2.52, \mathrm{P}=0.008)$, other Hispanic $(\mathrm{OR}=1.46,95 \% \mathrm{Cl}: 1.11-1.93, \mathrm{P}=0.008)$, and other ethnicity including multi-racial $(\mathrm{OR}=1.46,95 \% \mathrm{Cl}: 1.11-1.93, \mathrm{P}=0.008)$ children were significantly more likely to experience wheezing compared to Mexican-American children. 
Table 2

Association between early-life exposures and children wheezing, US, 2005-2012.

\begin{tabular}{|c|c|c|c|c|c|c|}
\hline Variables & & $\begin{array}{l}\text { Wheezing } \\
\text { cases n (\%) }\end{array}$ & $\begin{array}{l}\text { Healthy } \\
\text { children n } \\
\text { (\%) }\end{array}$ & $\begin{array}{l}\text { Unadjusted } \\
\text { OR (95\% } \\
\mathrm{Cl})\end{array}$ & $\begin{array}{l}\text { Adjusted } \\
\text { OR } \\
(95 \% \\
\text { Cl)* }\end{array}$ & $\begin{array}{l}P \\
\text { value* }\end{array}$ \\
\hline \multirow{3}{*}{$\begin{array}{l}\text { Maternal } \\
\text { smoking } \\
\text { during } \\
\text { pregnancy }\end{array}$} & No & 1365(82.03) & 9985(87.72) & 1 (ref.) & 1 (ref.) & \multirow[t]{2}{*}{0.001} \\
\hline & Yes & 299(17.97) & 1398(12.28) & $\begin{array}{l}1.38(1.15 \\
1.65)\end{array}$ & $\begin{array}{l}1.42 \\
(1.15 \\
1.74)\end{array}$ & \\
\hline & Total & 1664(100) & 11383(100) & & & \\
\hline \multirow[t]{6}{*}{ Ethnicity } & $\begin{array}{l}\text { Mexican } \\
\text { American }\end{array}$ & $327(19.42)$ & $3280(28.47)$ & 1 (ref.) & 1 (ref.) & \\
\hline & $\begin{array}{l}\text { Other } \\
\text { Hispanic }\end{array}$ & 168(9.98) & 1130(9.81) & $\begin{array}{l}1.46(1.11 \\
1.93)\end{array}$ & $\begin{array}{l}1.46 \\
(1.11, \\
1.93)\end{array}$ & 0.008 \\
\hline & $\begin{array}{l}\text { Non-Hispanic } \\
\text { White }\end{array}$ & $490(29.10)$ & $3242(28.14)$ & $\begin{array}{l}1.49(1.23 \\
1.82)\end{array}$ & $\begin{array}{l}1.49 \\
(1.23 \\
1.82)\end{array}$ & 0.001 \\
\hline & $\begin{array}{l}\text { Non-Hispanic } \\
\text { Black }\end{array}$ & $559(33.19)$ & $2837(24.63)$ & $\begin{array}{l}2.03(1.63 \\
2.52)\end{array}$ & $\begin{array}{l}2.03 \\
(1.63 \\
2.52)\end{array}$ & 0.008 \\
\hline & $\begin{array}{l}\text { Other Race - } \\
\text { Including } \\
\text { Multi-Racial }\end{array}$ & 140(8.31) & 1030(8.94) & $\begin{array}{l}1.44(1.06 \\
1.96)\end{array}$ & $\begin{array}{l}1.46 \\
(1.11, \\
1.93)\end{array}$ & 0.008 \\
\hline & total & 1684(100) & 11519(100) & & & \\
\hline \multirow{6}{*}{$\begin{array}{l}\text { Socio- } \\
\text { economic } \\
\text { status }\end{array}$} & 1st quartile & 288(17.41) & 1790(16.20) & \multirow{6}{*}{$\begin{array}{l}0.98(0.93 \\
1.03)\end{array}$} & \multirow{6}{*}{$\begin{array}{l}0.98 \\
(0.93 \\
1.02)\end{array}$} & \multirow[t]{6}{*}{0.32} \\
\hline & 2nd quartile & $266(16.08)$ & 1755(15.88) & & & \\
\hline & 3rd quartile & $322(19.47)$ & 2038(18.45) & & & \\
\hline & 4th quartile & $392(23.70)$ & $2810(25.43)$ & & & \\
\hline & 5th quartile & $386(23.34)$ & 2656(24.04) & & & \\
\hline & total & $1654(100)$ & $11049(100)$ & & & \\
\hline $\begin{array}{l}\text { anyone smoke } \\
\text { inside home }\end{array}$ & No & 1406(83.59) & $9859(86.26)$ & 1 (ref.) & 1 (ref.) & \\
\hline
\end{tabular}

* Adjusted odds ratios for the including variables in confounding paths; OR: Odds Ratio; $\mathrm{Cl}$ :

Confidence Interval

** P-value for adjusted models. 




\section{Discussion}

In this large population-based 8-year study conducted on children in the US, we indicated that odds of wheezing were higher in children who had MSDP than children without this exposure. Although SES and birth weight were negatively associated with childhood wheezing, these associations were not statistically significant. Maternal age at pregnancy and having smoker family member were also recognized as potential risk factors for childhood wheezing; however, the results did not establish significant associations. Importantly, all the studied ethnicities (i.e. non-Hispanic White, non-Hispanic black, other Hispanic, and other ethnicity including multi-racial) except for the Mexican-American were identified as significant risk factors for childhood wheezing. All these associations were adjusted for the potential cofounding effects of the variables identified in the DAG analysis. The previous reports were 
consistent with our finding on the association between the history of MSDP and childhood wheezing. In a recent cohort study in which infants were followed during the first year of life, maternal active smoking significantly increased the risk of wheezing in infants $(\mathrm{OR}=2.09,95 \% \mathrm{Cl}: 1.54-2.84, \mathrm{p}<0.0001)(15)$. In accordance with our observation, no associations were reported between wheezing and neither SES (OR $=0.81,95 \% \mathrm{Cl}: 0.61-1.07, \mathrm{p}=0.151)$ nor birth weight $(\mathrm{OR}=0.98,95 \% \mathrm{Cl}: 0.89-1 \cdot 07, \mathrm{P}=0.614)$ in the recent report (15). The impact of cigarette smoking on in-utero biological development of fetus has been ascertained (15). Overall, these statements are consistent with our findings. In fact, smoking exposure may impair the lung development and growth secondary to the detrimental effects of nicotine which interferes with lung growth and increases collagen deposition in airways (15).

Vardavas et al $(16,17)$ in a pooled analysis reported that prenatal exposure to smoke increased the risk of postnatal wheezing in children. This was consistent with our findings as we also observed that MSDP had a significant association with childhood wheezing, while post-natal exposure to smoke by having smoker family members did not exert such effect. Furthermore, according to the report of Moradzadeh et al in 2018 (10), maternal smoking moderately increased the odds of childhood asthma after adjustment for the misclassification bias of self-reported exposure. As the rate of MSDP has been unacceptably high (as high as $15.9 \%$ ) among US women $(18,19)$, the detrimental effects of this event on fetus and infants are concerning. Whitney et al (18) underscored that the rate of MSDP was significantly different among various ethnicities. In fact, MSDP may role as an intermediate variable influencing the association between ethnicity and childhood wheezing. As we observed here, there was a significant association between ethnicity and wheezing. This may be partly due to the high prevalence of smoking in mothers of the at risk ethnicities. Similar to our finding, the SES was not significantly associated with childhood wheezing in the study of Vanker et al as well (15). Therefore, these observations indicated that ethnicity may present a stronger interrelationship with cigarette smoking than SES to determine the risk of childhood wheezing.

Our results further confirmed the findings of the Millennium Cohort Study (a national wide study on children born in UK) by Taylor-Robinson et al. (20). In the recent study, no significant association was identified between low birth weight and childhood wheezing $(\mathrm{OR}=0.97)(20)$. However, the birth weight may be considered as a mediator influencing the interaction between MSDP and wheezing. In fact, the non-significant association between birth weight and wheezing may be due to the superior impact of MSDP on the risk of childhood wheezing. In line with our study, no statistically significant association was reported between birth weight and childhood wheezing in a cohort study by Vanker et al (15) and a systematic review and meta-analysis by Mebrahtu et al (21).

Our study did not support any statistically significant link between maternal age at pregnancy and the odds of childhood wheezing. This was consistent with the results of two cohort studies by Caudri et al in Netherlands (22) and Kotecha et al in United Kingdom (23).

The strengths of this study included using the data related to a relatively long period of time (i.e. 8 years) and incorporating a large sample size obviating any sampling error. Our results also presented a low 
possibility of selection bias because of a high response rate and the complex sampling method.

Some limitations should be considered for this study. The variables studied in NHANES are based on selfreporting (10); therefore, there is a risk for misclassification bias $(10,24,25)$ due to problems with the recalling and under-reporting (14). The adjusted ORs (considering the possible misclassification of selfreported MSDP) were bigger than the respective unadjusted values in this study. So, assuming misclassification bias in self-reported MSDP, the obtained ORs in this study were smaller than those in reality. Nevertheless, self-reporting has been the standard method for collecting data on wheezing in large epidemiological studies such as the International Study of Asthma and Allergies in Childhood. In order to assess the impact of misclassification bias on the findings, it is recommended to obtain bias-adjusted ORs by performing bias analysis for exposures, confounders, and self-reported wheezing. In addition, mediation analysis is necessary to calculate the direct and indirect impacts of any other variable on the risk of childhood wheezing.

In conclusion, a history of MSDP, as well as ethnicity remained independent and important risk factors of childhood wheezing in a large US population after adjustment for well-known confounders. This study highlighted the need for implementing effective programs to prevent women from smoking before and during pregnancy. The study also highlighted the importance of ethnicity as a risk factor for childhood wheezing. Therefore, it may be logical to consider preventive measures among high-risk ethnicities. Our results also underscored that exposures during prenatal period may exert a larger impact on the risk of childhood wheezing. Further studies are needed to divulge other unknown confounders and their effects on respiratory tract health.

\section{Declarations}

\section{Conflict of interest:}

The authors declare that they have no competing interests.

\section{Author Contributions:}

Conceptualization: RM, MZ. Formal analysis: RM, MZ. Methodology: RM, MZ. Writing - original draft: RM, MZ. Writing - review \& editing: RM, MZ.

\section{References}

1. Muglia C, Oppenheimer JJCA, Reports A. Wheezing in Infancy: An Overview of Recent Literature. 2017;17(10):67.

2. Stenberg-Hammar K, Hedlin G, Söderhäll C. Rhinovirus and preschool wheeze. 2017;28(6):513-20. 
3. Silvestri M, Franchi S, Pistorio A, Petecchia L, Rusconi F. Smoke exposure, wheezing, and asthma development: A systematic review and meta-analysis in unselected birth cohorts. 2015;50(4):353-62.

4. Azad MB, Vehling L, Lu Z, Dai D, Subbarao P, Becker AB, et al. Breastfeeding, maternal asthma and wheezing in the first year of life: a longitudinal birth cohort study. 2017;49(5):1602019.

5. Patel SP, Järvelin M-R, Little MP. Systematic review of worldwide variations of the prevalence of wheezing symptoms in children. Environmental health : a global access science source. 2008;7:57-.

6. Mebrahtu TF, Feltbower RG, Parslow RC. Incidence and Burden of Wheezing Disorders, Eczema, and Rhinitis in Children: findings from the Born in Bradford Cohort. 2016;30(6):594-602.

7. Rothman KJ, Greenland S, Lash TL. Modern Epidemiology. Third Edition ed. Philadelhia, USA: Lippincott Williams \& Wilkins; 2008.

8. Hernan MA, Robins JM. Causal Inference. Chapman \& Hall/CRC: Taylor \& Francis; 2019.

9. Centers for Disease Control and Prevention. National Health and Nutrition Examination Survey. 2019; http://www.cdc.gov/nchs/nhanes.htm. Accessed May 4th, 2019.

10. Moradzadeh R, Mansournia MA, Baghfalaki T, Nadrian H, Gustafson P, McCandless LC. The impact of maternal smoking during pregnancy on childhood asthma: adjusted for exposure misclassification; results from the National Health and Nutrition Examination Survey, 2011-2012. Annals of Epidemiology. 2018;28(10):697-703.

11. Moradzadeh R, Nadrian H, Golboni F, Kazemi-Galougahi MH, Moghimi N. Economic inequalities amongst women with osteoporosis-related fractures: an application of concentration index decomposition. Health promotion perspectives. 2016;6(4):190-5.

12. Kazemi-Galougahi MH, Mansouri A, Akbarpour S, Bakhtiyari M, Sartipi M, Moradzadeh R. Incomerelated inequality in completed suicide across the provinces of Iran. Epidemiol Health. 2018;40(0):e2018012-0.

13. Siegerink B, Dekker FW, Suttorp MM, Jager KJ, Zoccali C. Graphical presentation of confounding in directed acyclic graphs. Nephrology Dialysis Transplantation. 2014;30(9):1418-23.

14. Moradzadeh R, Mansournia MA, Ghiasvand R, Baghfalaki T, Nadrian H, Holakouie-Naieni K. Impact of Age at Menarche on Breast Cancer: The Assessment of Recall Bias. 2019;22(2):65-70.

15. Vanker A, Barnett W, Workman L, Nduru PM, Sly PD, Gie RP, et al. Early-life exposure to indoor air pollution or tobacco smoke and lower respiratory tract illness and wheezing in African infants: a longitudinal birth cohort study. The Lancet Planetary Health. 2017;1(8):e328-e36.

16. Vardavas $\mathrm{Cl}$, Hohmann C, Patelarou E, Martinez D, Henderson AJ, Granell R, et al. The independent role of prenatal and postnatal exposure to active and passive smoking on the development of early wheeze in children. European Respiratory Journal. 2016;48(1):115-24.

17. Zairina E. Maternal passive smoking and the risk of developing wheeze in children: how should we deal with it? 2016;48(1):3-5.

18. Witt WP, Mandell KC, Wisk LE, Cheng ER, Chatterjee D, Wakeel F, et al. Predictors of alcohol and tobacco use prior to and during pregnancy in the US: the role of maternal stressors. 2015;18(3):523- 
37.

19. Substance Abuse and Mental Health Services Administration, Results from the 2013 National Survey on Drug Use and Health: Summary of National Findings, NSDUH Series H-48, HHS Publication No. (SMA) 14-4863. Rockville, MD: Substance Abuse and Mental Health Services Administration, 2014. .

20. Taylor-Robinson DC, Pearce A, Whitehead M, Smyth R, Law C. Social inequalities in wheezing in children: findings from the UK Millennium Cohort Study. 2016;47(3):818-28.

21. Mebrahtu TF, Feltbower RG, Greenwood DC, Parslow RC. Birth weight and childhood wheezing disorders: a systematic review and meta-analysis. 2015;69(5):500-8.

22. Caudri D, Savenije OEM, Smit HA, Postma DS, Koppelman GH, Wijga AH, et al. Perinatal risk factors for wheezing phenotypes in the first 8 years of life. 2013;43(12):1395-405.

23. Kotecha SJ, Watkins WJ, Lowe J, Granell R, Henderson AJ, Kotecha S. Comparison of the Associations of Early-Life Factors on Wheezing Phenotypes in Preterm-Born Children and Term-Born Children. American Journal of Epidemiology. 2019;188(3):527-36.

24. Moradzadeh R, Mansournia MA, Baghfalaki T, Ghiasvand R, Noori-Daloii MR, Holakouie-Naieni K. Misclassification Adjustment of Family History of Breast Cancer in a Case-Control Study: a Bayesian Approach. Asian Pacific Journal of Cancer Prevention. 2016;16(18):8221-6.

25. Moradzadeh R, Golmohammadi P, Kazemi-Galougahi MH, Sartipi M, Sharfi H, Ahmadpour M. Distribution of breast cancer risk factors in two groups of healthy people referral to cancer registry and Shahid Mottahari center. Data in Brief. 2018;19:988-91.

\section{Figures}


Figure 1: DAG for included variables on confounding paths. (SES: Socio-economic status; MSDP: Maternal smoking during pregnancy)

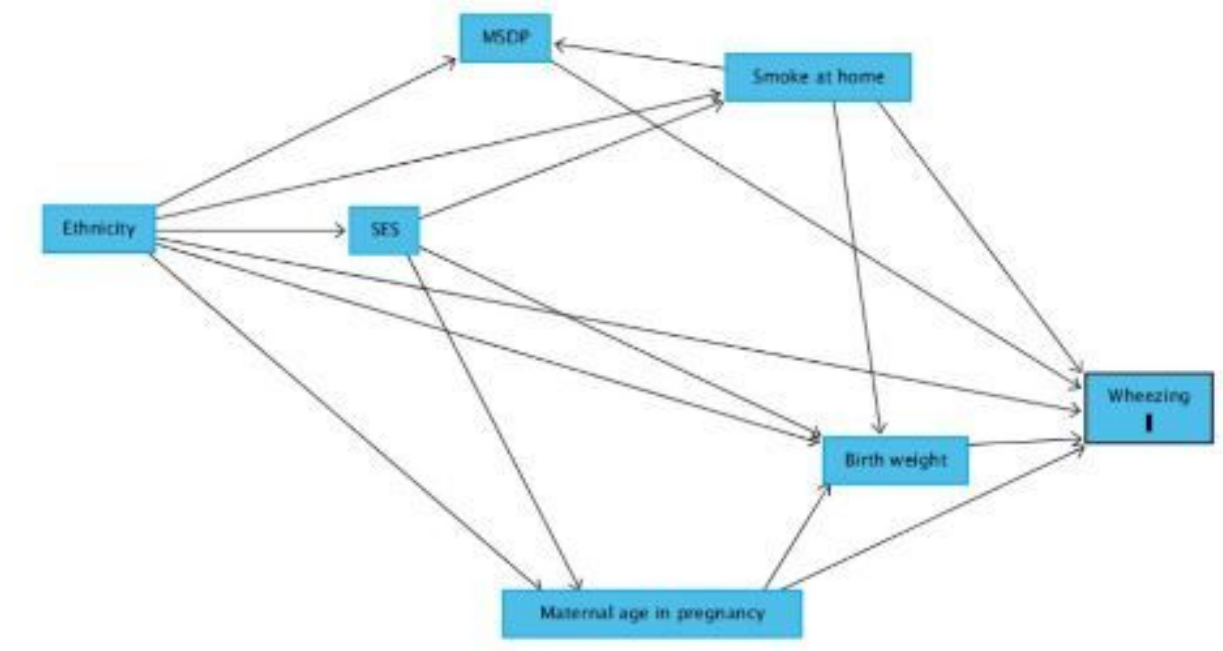

Figure 1

Figure 1 